\title{
The Competition Model: the Input, the Context, and the Brain
}

\author{
Brian MacWhinney \\ To appear in 'Cognition and Second Language Instruction' \\ edited by Peter Robinson, Cambridge University Press.
}

Language learning is a three-way interaction between the input, the learner, and the interactional context (Bloom, 1974). This three-way interaction provides a general framework for understanding first and second language acquisition, in both naturalistic and formal contexts. In order to elaborate this general framework, we need to model its three components:

1. The input. We need to know how the linguistic input can be structured to maximize effective learning. What aspects of the phonology, syntax, semantics, and morphology of the input does the learner use to "crack the code" of the new language?

2. The learner. We need to understand exactly how the cognitive abilities of the learner shape the process and outcome of second language instruction.

3. The context. Traditionally, the classroom environment maintains a rather uniform structure in which interaction is controlled by the instructor. How does this framework affect learning and how can it be varied to improve the learning process?

This paper will examine these three components within the framework of the Competition Model (MacWhinney, 1987; MacWhinney \& Bates, 1989). To quantify the role of the input in second language learning, the model relies on the concepts of cue reliability and availability. To characterize the cognitive abilities of the learner, the model relies on findings from cognitive neuroscience. To understand the role of the context, the model elaborates the concepts of environmental and social support. The Competition Model views both first and second language learning as constructive, data-driven processes that rely not on universals of linguistic structure, but on universals of cognitive structure. It attributes development to learning and transfer, rather than to the principles and parameters of Universal Grammar (Chomsky, 1965).

\section{The Input}

The Competition Model is designed to quantify the ways in which distributional properties of the input control language learning and language processing. The basic claim of the model in regard to input is that language comprehension is based on the detection of a series of cues and the reliability and availability of these determines the strength of cues in comprehension. The model contrasts sharply with generative grammar in this regard. Generative grammar views language through the lens of abstract trees in a universal deep structure. The Competition Model recognizes the importance of surface phrase structure, but relates all sentence processing to cue detection and interpretation. Those cues that are highest in reliability and availability are the ones that most strongly control comprehension and which are acquired first during language learning.

In order to elaborate this simple relation between cues and comprehension, we need to specify how languages distribute cues across sentences. To do this, the Competition Model has turned to crosslinguistic studies of sentence processing. In particular, the forms or 
cues that we have studied empirically include nominal case-marking, word order patterns, stress patterns, noun-verb agreement markers, clitic pronouns, and verb voice markings. We have studied the use of these cues in Arabic (Taman, 1993), Bulgarian (Andonova, 1998), Chinese (Bates, Chen, Tzeng, Li, \& Opie, 1991; Li, Bates, Liu, \& MacWhinney, 1992; Liu, Bates, \& Li, 1992; Tzeng, Chen, \& Hung, 1991), Dutch (Kilborn \& Ito, 1989; McDonald, 1986; McDonald, 1987a; McDonald, 1987b), English (Bates, McNew, MacWhinney, Devescovi, \& Smith, 1982; MacWhinney \& Bates, 1978; MacWhinney, Bates, \& Kliegl, 1984), French (Kail, 1989), Hebrew (Sokolov, 1989), Hindi (Vaid \& Pandit, 1991), Hungarian (Bates et al., 1984; MacWhinney \& Osman-Sági, 1991; MacWhinney, OsmanSági, \& Slobin, 1991; MacWhinney \& Pléh, 1988; MacWhinney \& Pléh, 1997; MacWhinney, Pléh, \& Bates, 1985), Italian (Bates et al., 1984; Bates et al., 1982), Japanese (Kilborn \& Ito, 1989; Sasaki, 1994; Sasaki, 1997a; Sasaki, 1997b), Russian (Kempe \& MacWhinney, 1998), Spanish (Kail, 1989), Turkish (MacWhinney et al., 1991), and Warlpiri (Bavin \& Shopen, 1989).

Much of the crosslinguistic work conducted in the Competition Model framework has focused on the use of cues to agent identification. To illustrate the ways in which surface cues mark grammatical functions, let us focus on the case of agent identification in simple sentences with two nouns and a verb, such as "The boy is annoying the parrots". Figure 1 presents a simple connectionist model for the cues to agent identification in English. This network takes as input various combinations of these seven cues:

1. pre: preverbal positioning (placing "the boy" before "is annoying" in "the boy is annoying the parrots"),

2. agr: verb agreement morphology (marking "is" to agree in number with "the boy", rather than "the parrots"),

3. init: sentence initial positioning (placing "the boy" at the beginning of the sentence),

4. nom: nominative case-marking for pronouns ("I" vs. "me" as a marker of the subject in English),

5. the: use of the article "the".

6. by: the attachment of the preposition "by" to mark the agent in a passive, and

7. pas: the presence of passive morphology on the verb.

8.

For example, if the input sentence is "the boy is annoying the parrots", then the input nodes activated are "pre", "agr", "init", and "the". The node for "nom" is not activated because "boy" is a noun and there is no case-marking for nouns in English. The nodes for the "by" and "pas" cues are not activated, because the sentence is not a passive.

In a connectionist neural network, activation of the input units is passed on to the hidden units and, from there, to the output units at the top of the figure.

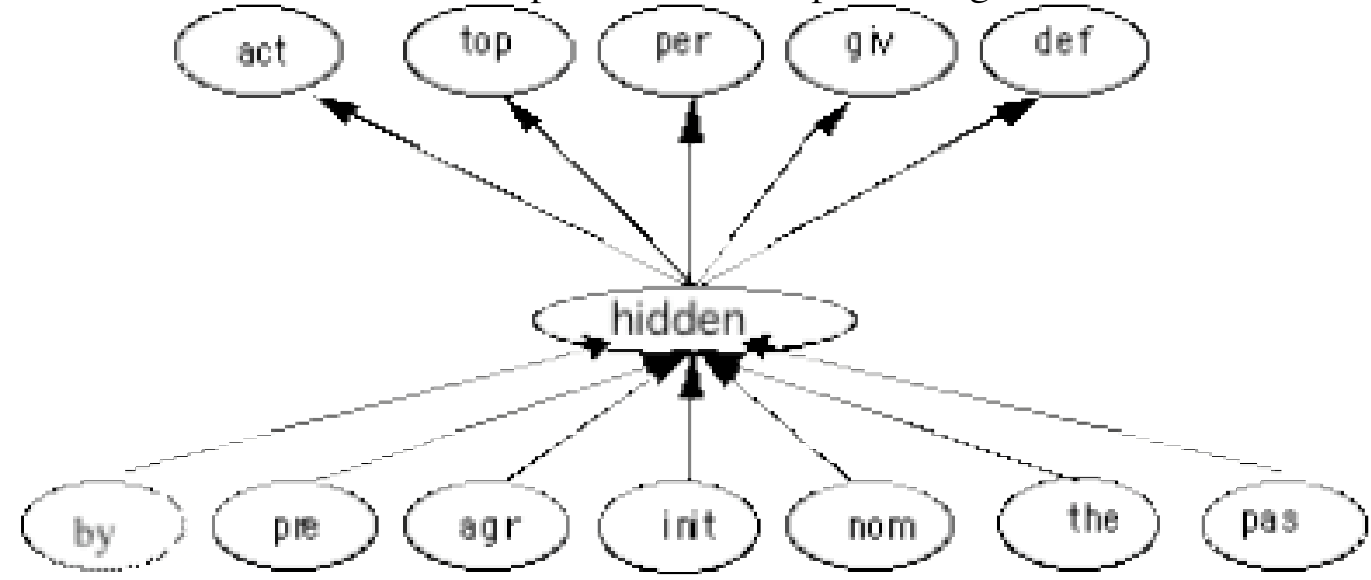


Figure 1: A network for relating subject-marking forms to subject functions in English.

The network produces as output a series of functional interpretations, including actor (act), topicality (top), perspective (per), givenness (giv), and definiteness (def). In our crosslinguistic experiments, we are usually most interested in finding out which of two or three nouns in a sentence ends up being selected as the actor. This means that the activations of the output nodes at the top of Figure 1 also feed into additional nodes that arbitrate between a series of word competitors. In the sentence "the boy is annoying the parrots", the "act" output unit is turned on more strongly for the noun "boy" than for the noun "parrots". As a result, "the boy" wins the competition for assignment to the role of actor. It is this competition that gives the Competition Model its name.

Variations in the pattern activated across the input units will lead to variations in the output. For example, if the input were "He was chased by the dog", the "pre", "agr", "init", and "nom" units would be activated for "he". However, the units for "by", "agr", "the", and "pas" would be activated for "the dog". A young child might have troubles understanding the passive. However, by the age of four or five, the child has learned that, when the "by" and "pas" units are turned on, they must dominate the other units and select "the dog" as the agent in the output.

During sentence production, the connections in Figure 1 operate in the opposite direction. Unlike the Garrett-Levelt model (Levelt, 1989), the Competition Model assumes that lexical items are activated before full syntactic frames are composed. This means that, when production begins, we may have a couple of nominals available, such as "the boy" and "the parrots". We know that "the boy" is the actor and the topic. Our goal is to figure out which forms to activate in order to express this fact. Because the functions of "actor" and "topic" are not dissociated in this case, we will want to treat "the boy" as a subject by assigning it to the preverbal position and making the verb agree with it. Thus, "the boy" wins out in the competition for preverbal positioning and the nominal "the parrots" wins in the competition for postverbal positioning.

Figure 1 includes an additional layer of connections called "hidden units". Connectionist models use these additional units to facilitate the learning of nonlinear associations between inputs (functions) and outputs (forms). Nonlinearities arise when cue A has one effect in the presence of cue B, but an exactly opposite effect in the presence of cue C. A good example of such nonlinear associations occurs in the choice of the passive voice in English. In the active voice, the actor wins the competition for preverbal position. However, in the passive voice, it loses out to the object and is forced to take a backseat in the "by-clause". This "flip-flop" between two competing interpretations of the same surface cue of preverbal positioning is mediated by the presence or absence of the additional cue of passive morphology on the verb. If the verb has the passive morphology, the normal interpretation is reversed. This relation between the cues involved is a good example of a nonlinear association.

The architecture of connectionist systems of the type diagrammed in Figure 1 provides us with several ways of thinking about the interplay between cooperation and competition. In natural dialog, communicative functions tend to cooccur in a state of peaceful coexistence. For example, it is often the case that the topic of a sentence is also agential, given, definite, and perspectival. Together, these five functions form a cluster of cooccuring, mutually compatible relations that activate a set of parallel linguistic devices such as preverbal positioning and unmarked stress. These correlations between functions are reflections of real correlations in the world. Because the functions we choose to talk 
about are highly correlated in real life, the forms we use to talk about these functions also become highly correlated. This makes it so that no single form expresses any single function and the relation between forms and functions is both fluid and complex. There are also important correlations on the level of forms. For example, words that take the article "the" also are capable of taking the plural suffix, and so on (Maratsos \& Chalkley, 1980).

The cooperation that exists in coalitions is balanced by the competition that exists between major form alternatives. For example, only one noun phrase in a sentence can be the agent and only one can be the patient. This means that there is a direct competition between agent marking and patient marking, as schematized in Figure 2. Competitions of this type exist on all levels of language processing. Words compete for lexical activation, phrases compete for syntactic ordering position, and sounds compete for insertion into syllabic slots. In comprehension, alternative sound forms compete for lexical activation, and alternative interpretations compete for phrase and case role assignments.

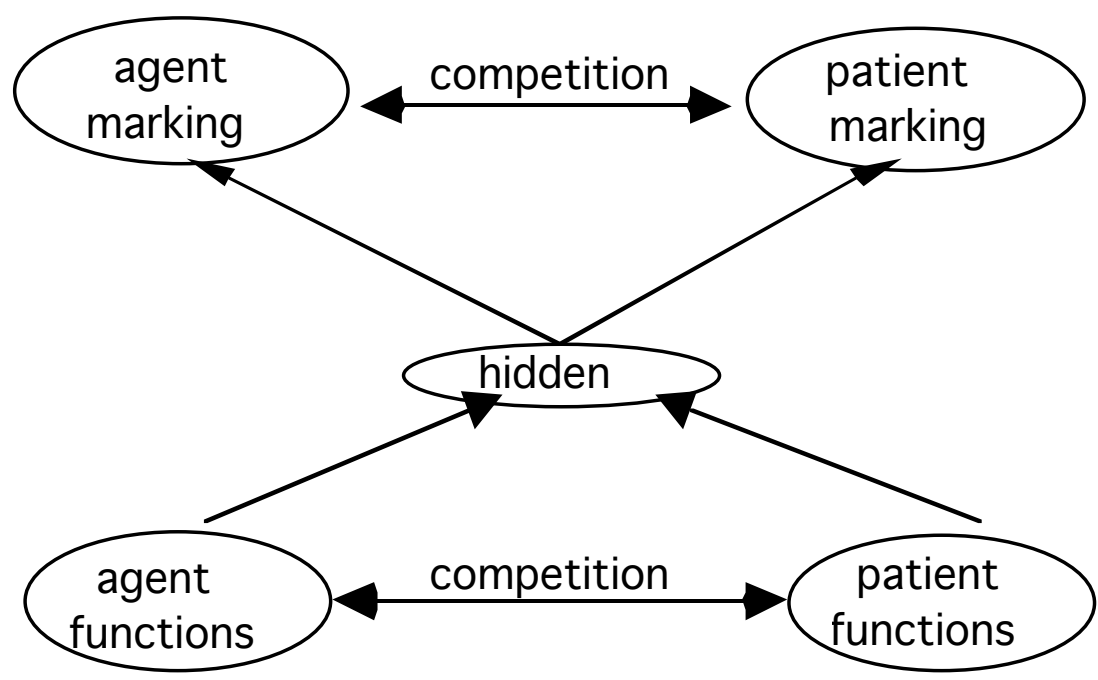

Figure 2: A network illustrating the competition between case roles in English.

All of this cooperation and competition works against a background of probabilistic activations that leads to a system rich in category leakage. Leakage arises when a form that is normally associated with a certain function starts to be viewed occasionally as expressing some related, but different function. The root cause of category leakage is the fact that, even before the leakage becomes obvious, there is often no single function that is uniquely associated with a given form. Instead, several allied functions may coexist peacefully, because they coexist peacefully in the world around us. For example, it is typically the case that a "causor" is also an "initiator", and the functions of "causor" and "initiator" tend to coexist peacefully. Over time, the functional weight of a given marking can change so that what was originally a secondary function starts to emerge as the primary function. MacWhinney (1989) examines cases of reinterpretation of this type in the historical development of case-marking in Hungarian.

The basic empirical claim of the Competition Model is that the learning of the system of form-function mappings we have discussed is driven by cue reliability. Reliability is the conditional probability that an interpretation $X$ should be selected given the presence of a cue $\mathrm{Y}$, i.e. $\mathrm{p}(\mathrm{XIY})$. If this probability is high, then $\mathrm{Y}$ is a reliable cue to $\mathrm{X}$. The most straightforward prediction from this initial analysis is that forms with a high conditional 
probability should be acquired early and should be the strongest determinants of processing in adults.

A more complete treatment of the general topic of cue validity distinguishes four cue distribution dimensions. We are particularly interested in the ways in which these four dimensions end up contributing to cue strength as measured in our psycholinguistic experiments.

1. Task frequency. The most basic determinant of cue strength is the raw frequency of the basic task. Some tasks are incredibly frequent. For example, the task of locating an object in space is something that we routinely do as frequently as once each second. Other tasks may be quite rare. For example, we are seldom called upon to determine the rotational momentum of planetary bodies. Linguistic tasks are often of intermediate frequency. The task of determining the agent of the verb occurs with virtually every transitive verb. The task of determining anaphoric reference occurs every time a pronoun is encountered. Because most basic linguistic tasks are well above threshold frequency, the dimension of task frequency is seldom an important determinant of relative cue strength. However, in the case of a second language that was used extremely infrequently, task frequency could become a factor determining a general slow-down in acquisition.

2. Availability. Within a given task, cues will vary in their relative availability. We can call the relative availability of a cue for a given task its "simple availability". Usually, however, we are interested not just in knowing whether a cue is present, but also whether or not it has any contrastive effect. This is called "contrast availability". For example, the cue of subject-verb agreement in English is present in nearly every English clause. However, in many sentences, the verb agrees with two or more candidate subjects. In a sentence like "The cat chases the dog", the fact that the verb is marked for a singular subject tells us nothing about the status of the subject, since both nouns are singular. In this example, the agreement cue is available, but not contrastively. However, in a sentence like "the cat chases the dogs", only the first noun agrees with the verb and the agreement cue is both available and contrastive. This example shows that an available cue is only useful if it is also contrastive

3. Simple reliability. The most important and most basic cue validity dimension is the dimension of reliability. A cue is reliable if it leads to the right functional choice whenever it is present.

4. Conflict reliability. In addition to simple reliability, cues can be characterized in terms of their conflict reliability vis a vis some other particular cue.

Most Competition Model experiments use a simple, basic, sentence interpretation procedure. Subjects are given a sentence with two nouns and a verb and are asked to say who was the actor. In a few studies, the task involves direct-object identification (Sokolov, 1988; Sokolov, 1989), relative clause processing (MacWhinney \& Pléh, 1988), or pronominal assignment (MacDonald \& MacWhinney, 1990; McDonald \& MacWhinney, 1995), but most often the task is agent identification. Sometimes the sentences are wellformed grammatical sentences like "the cat is chasing the duck". Sometimes they involve competitions between cues, as in the ungrammatical sentence "*the duck the cat is chasing". Depending on the language involved, the cues varied in these studies include word order, subject-verb agreement, object-verb agreement, case-marking, prepositional case marking, stress, topicalization, animacy, omission, and pronominalization. These cues are varied in a standard orthogonalized ANOVA design with three or four sentences per cell to increase statistical reliability. The basic question being asked is always the same: what is the relative order of cue strength in the given language and how do these cue strengths interact? 
These studies have yielded a remarkably consistent body of results. The most important finding is that the order of cue strength found in our experiments with adults always corresponds with the order of cue reliability yielded by text counts in the language. In different languages, we find different cue dominance patterns. In English, the dominant cue for subject identification is preverbal positioning. For example, the English sentence "the eraser hits the cat" is interpreted as having "the eraser" as the agent. However, a parallel sentence in Italian or Spanish, would have "the cat" as the agent. In Spanish, the prepositional object marker "a" is a clear cue to the object and the subject is the noun that is not the object. An example of this is the sentence "El toro mató al torero" (The bull killed to-the bullfighter). No such prepositional cues exists in English. In German, case marking on the definite article is a powerful cue to the subject. In a sentence such as "Der Lehrer liebt die Witwe" (The teacher loves the widow), the presence of the nominative masculine article "der" is a sure cue to identification of the subject. In Hungarian, the subject is the noun not marked by any suffix or postposition. In Russian, the subject often has a case suffix. In Arabic, the subject is identified as the noun that agrees with the verb in number and gender and this cue is stronger than the case-marking cue. In French, Spanish, and Italian, when an object pronoun is present, it can help identify the noun that is not the subject.

Figures 3 and 4 illustrate the types of empirical data collected in these studies. In Figure 3, we see a comparison of English, German, and Italian in terms of the strength of use of the preverbal positioning word order cue in adults. In these graphs, percentage choice of the first noun as actor is graphed on the y-axis with sentence types varied on the $\mathrm{x}$-axis. It is clear that only English makes strong use of the word order cue. When the sentence has NVN order, English speakers interpret it overwhelmingly as SVO, despite the possible presence of agreement or animacy cues pointing in other directions. When the order is $\mathrm{NNV}$, listeners interpret it as OSV, relying on the fact that the noun before the verb is the actor. When the order is VNN, they interpret it as VOS, relying on the fact that the noun after the verb is the object. Germans and Italians make no strong use of any of these cues. In Figure 4, on the other hand, we see that Italians rely intensely on the agreement cue whenever it is present, despite possible contradictory signals from word order or animacy. It is cue usage patterns of this type that indicate the unique "footprint" of each of the languages we have studied. 


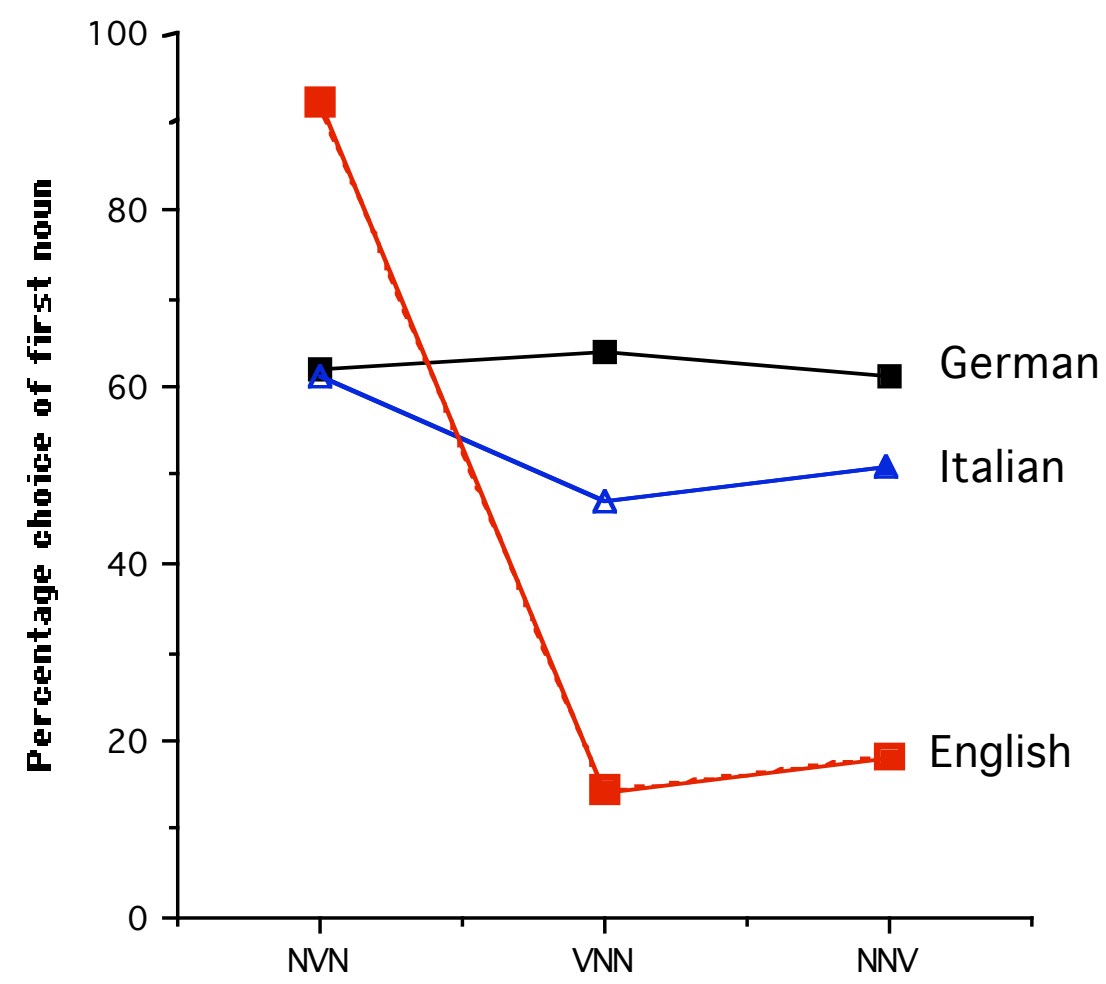

Figure 3: Language by Word Order Interaction for English, German, and Italian (Bates et al., 1982)

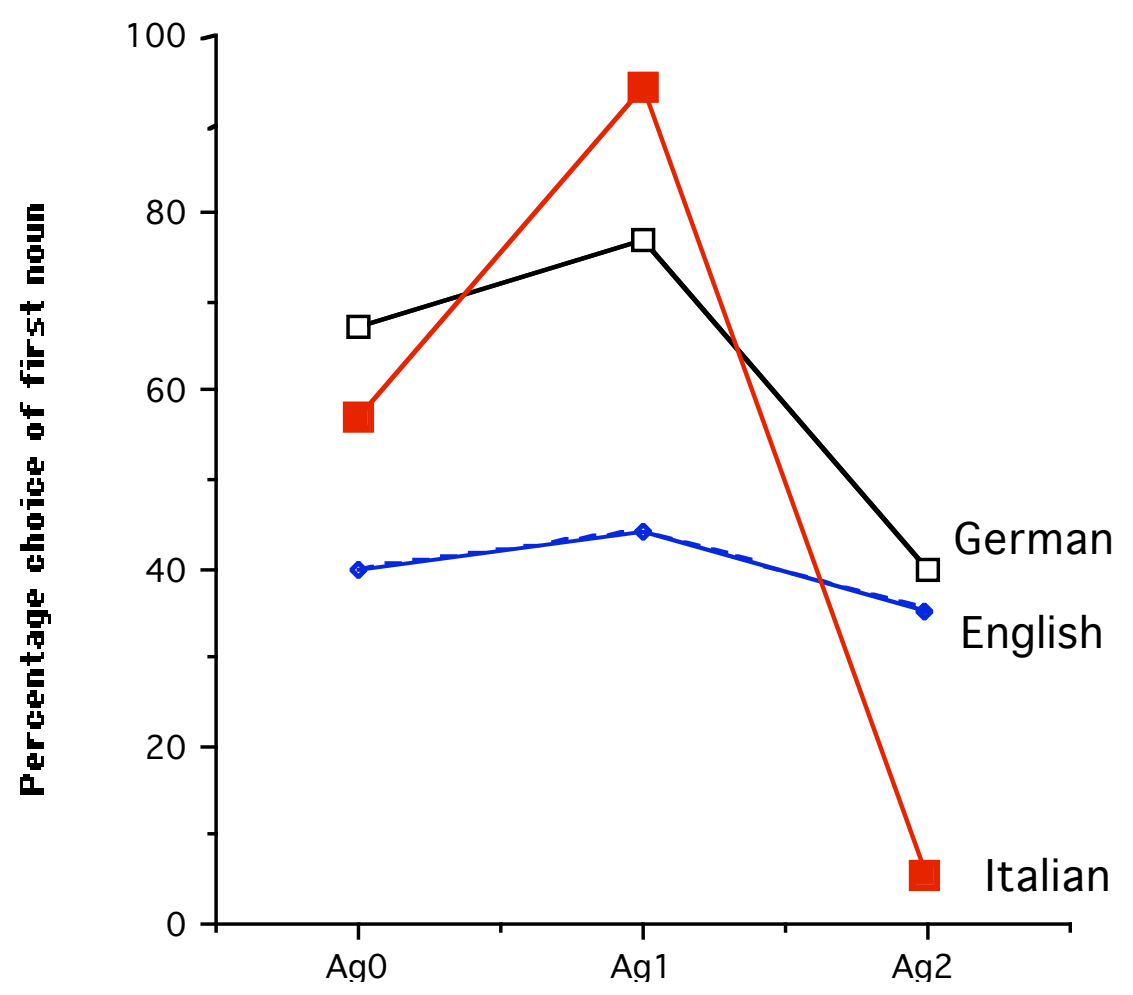


Figure 4: Language by Agreement Interaction for English, German, and Italian (MacWhinney et al., 1984).

The Competition Model provides a minimalist, empiricist prediction for the ways in which cues are acquired during first language acquisition. The prediction is that the first cue learned by the child should be the most reliable cue in the language and the order of acquisition of cues across the span of development should be determined by relative cue reliability. In general this prediction has held up. Figure 5 presents developmental data from three languages. In this graph, we see that word order is the predominant cue for children learning English and case-marking is the predominant cue for children learning Hungarian. However, we encountered a major violation of the predictions of the Competition Model for Italian children. If the children were to behave in accord with the cue reliability patterns found in text counts for adult Italian and the cue strengths evidenced by adult Italians, they would make far more use of agreement and far less use of word order. We have interpreted this failed prediction as evidence for additional cue cost factors that make it difficult for Italian children to pick up and use the agreement cue. These cue cost factors will be discussed in the section that deals with the characteristics of the learner.
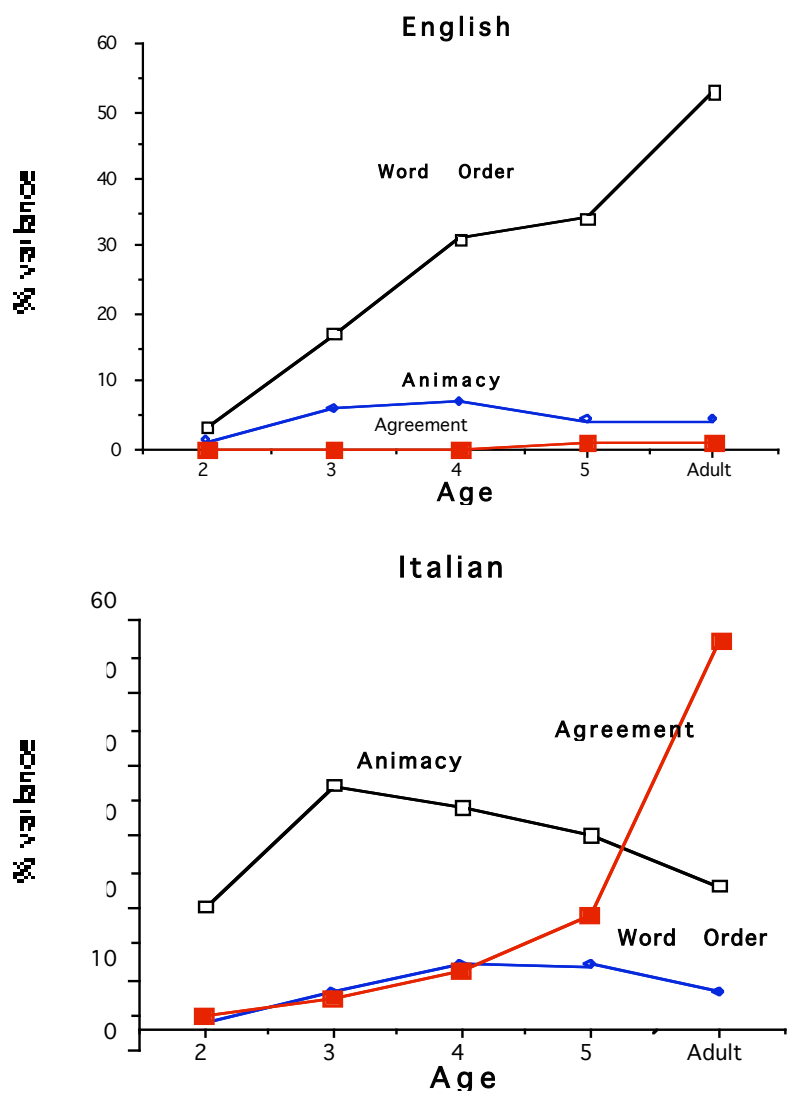


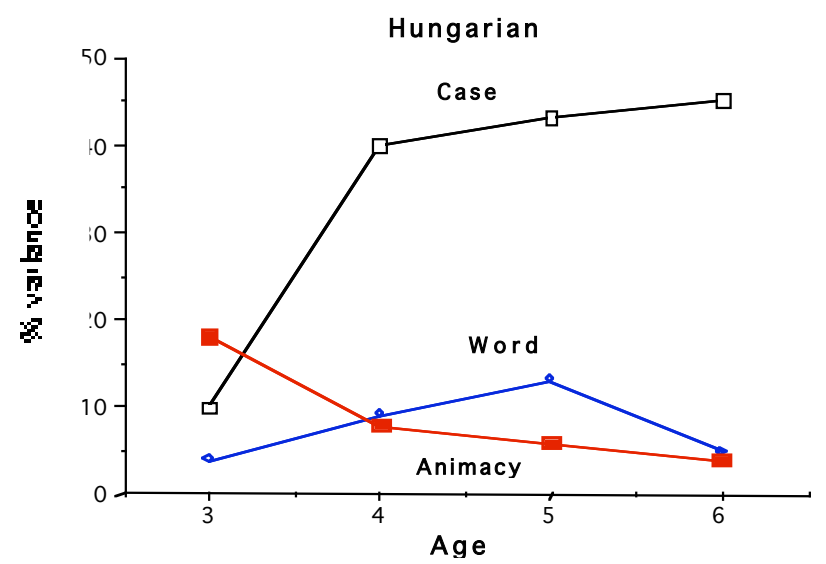

Figure 5: Changes in cue strength through development in English, Italian, and Hungarian. The y-axis in each panel is percentage variance accounted for in the ANOVA.

In addition to these basic findings regarding primary cue use, we have also found strong support for those aspects of the model that emphasize the ways in which cues interact through strength summation. Traditionally, interactive cue summation has been viewed as evidence for information integration (Anderson, 1982; Massaro, 1987; Oden \& Massaro, 1978). In fact, the Competition Model uses the same maximum likelihood mathematical modeling tools found in information integration theory (McDonald \& MacWhinney, 1989). What this means is that, when there is a sentence in which the cues for subject disagree, then choice is inconsistent. For example, people might disagree about the identity of the actor in an ungrammatical sentence like "are pushing the erasers the cat." In this sentence, agreement favors the choice of "the erasers"as actor, but animacy and the presence of "the erasers" in postverbal position favor "the cat". In this particular sentence, the crucial preverbal positioning cue is missing, so only weak cues are determining performance. If we look at a sentence like "The cats are pushing the erasers" we have no cue competition at all, since agreement, word order, and animacy are now all favoring "the cats". In general, by looking in detail at cells in which cues either compete or cooperate, we have found uniform support for the predictions of the Competition Model.

\section{The learner}

Students of second language acquisition have long recognized the importance of the learner. SLA models have often incorporated ideas from cognitive psychology regarding individual differences in attention, automaticity (Skehan and Foster, this volume; Schmidt, this volume), phonological rehearsal (Service \& Craik, 1993), short-term memory (Harrington, 1992; McLaughlin, 1982), long-term memory, auditory acuity, motivational levels, and learning styles (O'Malley \& Chamot, 1990). This "skills" approach to language learning has led to solid advances in our understanding of the second language process. However, it has not yet been tightly linked to information from the rapidly expanding field of cognitive neuroscience (Gazzaniga, 1997). In this section, I will suggest some ways in which facts about the human brain can help us build fuller models of second language acquisition.

The human brain is basically a huge collection of neurons. These neurons are connected through axons. When a neuron fires it passes activation or inhibition along thes axons and across synapses to all the other neurons with which it is connected. This passing of information occurs in an all-or-none fashion. There is no method for passing symbols down axons and across synapses. Brain waves cannot be used to transmit abstract objects 
such as phrase structures. Rather, it appears that the brain relies on a type of computation that emphasizes patterns of connectivity and activation. Models based on this type of computation are called "connectionist" models (Fausett, 1994), and they can be developed to offer computationally explicit accounts of second language learning. A fundamental feature of these models is that they view mental processing in terms of interaction and connection, rather than strict modularity and separation. Although connectionist models often postulate some types of modules, they tend to view these modules as emergent and permeable (MacWhinney, 1998), rather than innate and encapsulated (Fodor, 1983).

\section{Transfer}

The interconnected nature of the brain has a crucial consequence for second language acquisition theory. It means that the brain is structured in a way that promotes the transfer of information between emergent modules. Having acquired a first language during childhood, the second language learner comes to the task of learning the second language with a well-organized neurolinguistic system. Initially, the learning of the second language is highly parasitic on the structures of the first language in both lexicon (Kroll \& Sholl, 1992) and phonology (Flege \& Davidian, 1984; Hancin-Bhatt, 1994). When the learner first acquires a new L2 form, such as "silla" in Spanish, this form is treated as simply another way of saying "chair". This means that initially the L2 system has no separate conceptual structure and that its formal structure relies on the structure of L1. The learner's goal is to build up L2 representations as a separate system. This is done by increasing the direct linkage between new L2 forms and conceptual representations.

Given the fact that connectionism predicts such massive transfer for L1 knowledge to L2, we might ask why we do not see more error in second language learning. There are several reasons for this.

1. First, a great deal of transfer occurs smoothly and directly without producing error. Consider a word like "chair" in English. When the native English speaker begins to learn Spanish, it is easy to use the concept underlying "chair" to serve as the meaning for the new word "silla" in Spanish. The closer the conceptual, material, and linguistic worlds of the two languages, the more successful this sort of positive transfer will be. Transfer only works smoothly when there is close conceptual match. For example, Ijaz (1986) has shown how difficult transfer can be for Korean learners of English in semantic domains involving transfer verbs, such as "take" or "put". Similarly, if the source language has a two-color system (Berlin \& Kay, 1969), as in Dani, acquisition of an eight-color system, as in Hungarian, will be difficult. These effects underscore the extent to which L2 lexical items are parasitic on L1 forms.

2. Second, some types of transfer are quickly corrected. For example, when a learner tries to form a cognate in Spanish for the English noun "soap" the result is "sopa" which means "soup". Similarly, an attempt to transfer the English form "restrictions" to Spanish will run into problems, since the required target is "limitaciones", not "restriciones". Once an error like this is made, it will be quickly detected. Moreover, the learner will become increasingly sensitive to possible errors in cognate transfer.

3. Third, error is minimized when two words in L1 map onto a single word in L2. For example, it is easy for an L1 Spanish speaker to map the meanings underlying "saber" and "conocer" (Stockwell, Bowen, \& Martin, 1965) onto the L2 English form "know." Dropping the distinction between these forms requires little in the way of cognitive reorganization. It is difficult for the L1 English speaker to acquire this new distinction when learning Spanish. In order to control this distinction correctly, the learner must restructure the concept underlying "know" into two new 
related structures. In the area of lexical learning, it is these cases that should cause the greatest transfer-produced errors.

By building direct links between sound and meaning in L2, and by restructuring underlying concepts, the learner is able to increase the automaticity of lexical access in L2. This automaticity constitutes a "fire wall" against ongoing interference effects from L1 to L2. Consider the case of the English word "table" and the Spanish word "mesa". The construction of this fire wall in an adult learning Spanish as a second language requires the formation of links between the new Spanish word and other related Spanish words. At the same time, the concept underlying "mesa" will become linked to phrases and meanings that are more closely associated with the Spanish-speaking world than the English-speaking world. The more these two synonymous nouns can be linked into separate worlds and to other words in the same language, the stronger will be the fire wall that can prevent interference. This type of separation must be achieved not only on the lexical level, but also on the phonological, syntactic, and semantic levels. In effect, this work undoes the early parasitic association of concepts that the beginning second language learner used to bootstrap the first phases of learning. The end result of this process is the tightening of within-language links in contrast to between-language links. In this way, a certain limited form of emergent linguistic modularity is achieved. However, the establishment of a nonparasitic L2 lexicon does not produce full insulation between languages, even in the most advanced bilinguals (Grainger \& Dijkstra, 1992). The interactive nature of language processing continues to promote transfer and interference, even when the lexicons and grammars of both languages are fully established.

For those bilinguals and multilinguals who acquire their languages simultaneously during childhood, separate lexicons and grammars are constructed directly and there is no need to go through a process of undoing the initial connections formed through transfer (De Houwer, 1995; Grosjean, 1982). However, even in simultaneous bilinguals, some transfer and interference is predicted, due to the interactive nature of cognitive processing.

In phonology, the transfer of L1 articulatory patterns to L2 produces a foreign accent. In effect, the learner treats new words in L2 as if they were composed of strings of L1 articulatory units. This method of learning leads to short term gains at the expense of long term difficulties in correcting erroneous phonological transfer. However, even the most difficult cases of this negative transfer can be corrected through training and rehearsal (Flege, Takagi, \& Mann, 1995).

Transfer also affects the acquisition of grammar. If we think in terms of the Competition Model account of subject-marking devices presented earlier, we would say that the initial setting of weights in the parasitic L2 network is based on the weights in L1. However, learning of L2 involves more than simple weight tuning. In some cases, the second language requires the learner to seek out entirely new conceptual or discourse distinctions that were ignored in the first language, but which are now obligatory grammatical contrasts in the new language. A prime example of this type of restructuring might be the foreigner's attempts to pick up the category structure underlying the two major verbal conjugations of Hungarian. Every time a speaker of Hungarian uses a verb, he or she must decide whether it should be conjugated as transitive or intransitive. Making this choice is not a simple matter. The intransitive conjugation is used not only when the verb is intransitive, but also when the direct object is modified by an indefinite article or by no article at all. It is also used when it is in the first or second person, when the head of the relative clause is the object within the relative clause, when the direct object is quantified by words like "each," "no," and so on. For example, the "intransitive" conjugation is used when a Hungarian says "John runs," "John eats an apple," "John eats your apple," and "John eats no apple." On the other hand, the transitive conjugation is used when the object 
is definite, when it is modified by a third person possessive suffix, when it is possessed by a third person nominal phrase, and so on. Thus, the "transitive" or "definite" conjugation is used when the Hungarian wants to say "John eats the apple" or "John eats Bill's apple," whereas the intransitive is used to say "John eats an apple". There are some 13 conditions which, taken together, control the choice between the transitive and intransitive conjugations (MacWhinney \& Pléh, 1997). There is no single principle that can be used to group these 13 conditions. Instead, transitivity, definiteness, and referential disambiguation all figure in as factors in making this choice. This way of grouping together aspects of transitivity, definiteness, and possession is extremely foreign to most non-Hungarians. Not surprisingly, L2 learners of Hungarian have a terrible time marking this distinction; errors in choice of the conjugation of the verb are the surest syntactic cue that the learner is not a native Hungarian.

In order to acquire this new category, the L2 learner begins by attempting to transfer from L1. To some degree this can work. The learner attempts to identify the intransitive with the English intransitive. However, the fact that many sentences with objects also take the intransitive if the objects are somehow "indefinite" tends to block the simple application of this conceptual structure. In the end, the learner must be resigned to picking up the pieces of this new category one by one and restructuring them together into a working system. Here is an area where attempts at formal linguistic analysis on the learner's part only make matters worse. If the learner had proceeded like a Hungarian child (MacWhinney, 1974), he or she would have learned the conjugations by generalizing from a rich database of collocations and phrases. The adult needs to amplify this case-based approach to learning with a way of focusing on contrastive structures in which cues are competing. For the adult, such focusing on particularly difficult parts of a grammatical system will increase the efficiency of acquisition.

In many cases, the transfer of syntactic patterns from L1 to L2 is structurally correct, but pragmatically inaccurate. For example, Trévise (1986) observes that French speakers make excessive use of topicalization structures in English in the form of structures corresponding to left-dislocations, right-dislocations, and "c'est .. que" in French. Although these structures are all permissible in English, the actual conditions on their usage are far more restrictive than in French. Similarly, Seliger (1989) notes that Hebrew learners of English tend to systematically underuse the passive. He attributes this underusage to the relatively tighter, genre-dependent conditions on the use of the passive in Hebrew. In general, it is clear that simple transfer of an L1 structure to L2 is not sufficient to guarantee correct usage, since both underutilization and overutilization can occur until the full conditions governing the use of a construction in L2 are learned.

Our first investigations of second language processing effects (Bates \& MacWhinney, 1981) examined the comprehension of English sentences by a few of our academic colleagues. One subject was a native speaker of German who had lived in the United States for thirty years, was married to an American, and had published several important textbooks in experimental psychology written in English. Remarkably, we found that this subject processed simple English sentences using the cue strength hierarchy of German. This is to say, that he used agreement and animacy cues whenever possible, largely ignoring word order when it competed with agreement and animacy. This first evidence for the preservation of a syntactic "accent" in comprehension has now been supported in over a dozen studies across a wide variety of second language learning situations (Bates \& MacWhinney, 1981; de Bot \& van Montfort, 1988; Gass, 1987; Harrington, 1987; Kilborn, 1989; Kilborn \& Cooreman, 1987; Kilborn \& Ito, 1989; Liu et al., 1992; MacWhinney, Leinbach, Taraban, \& McDonald, 1989; McDonald, 1987a; McDonald, 1987b; McDonald \& Heilenman, 1991; McDonald \& MacWhinney, 1989). 
These Competition Model studies have used the sentence interpretation technique discussed earlier to estimate the strength of cues in second language learners. Because the experimental design places cues into competition, we can use mathematical techniques to estimate the strength of each cue in terms of its ability to determine the shape of our experimental data. We find uniformly that the learning of sentence processing cues in a second language is a gradual process. The process begins with L2 cue weight settings that are close to those for L1. Over time, these settings change in the direction of the native speakers' settings for L2. The pattern of results found in this research is perhaps most clearly represented by data from McDonald's studies of English-Dutch and Dutch-English second language learning (McDonald, 1987b). Figure 6 shows the decline in the strength of the use of word order by English learners of Dutch over increased levels of competence. In this graph the monolingual cue usage pattern for English is given in the first column and the monolingual Dutch pattern is given on the right. Between these two patterns, we see a declining use of word order and an increasing use of case inflection across three increasing levels of learning of Dutch. In Figure 7, we see exactly the opposite pattern for Dutch learners of English. These results and others like them constitute strong support for the application of the Competition Model to second language learning.

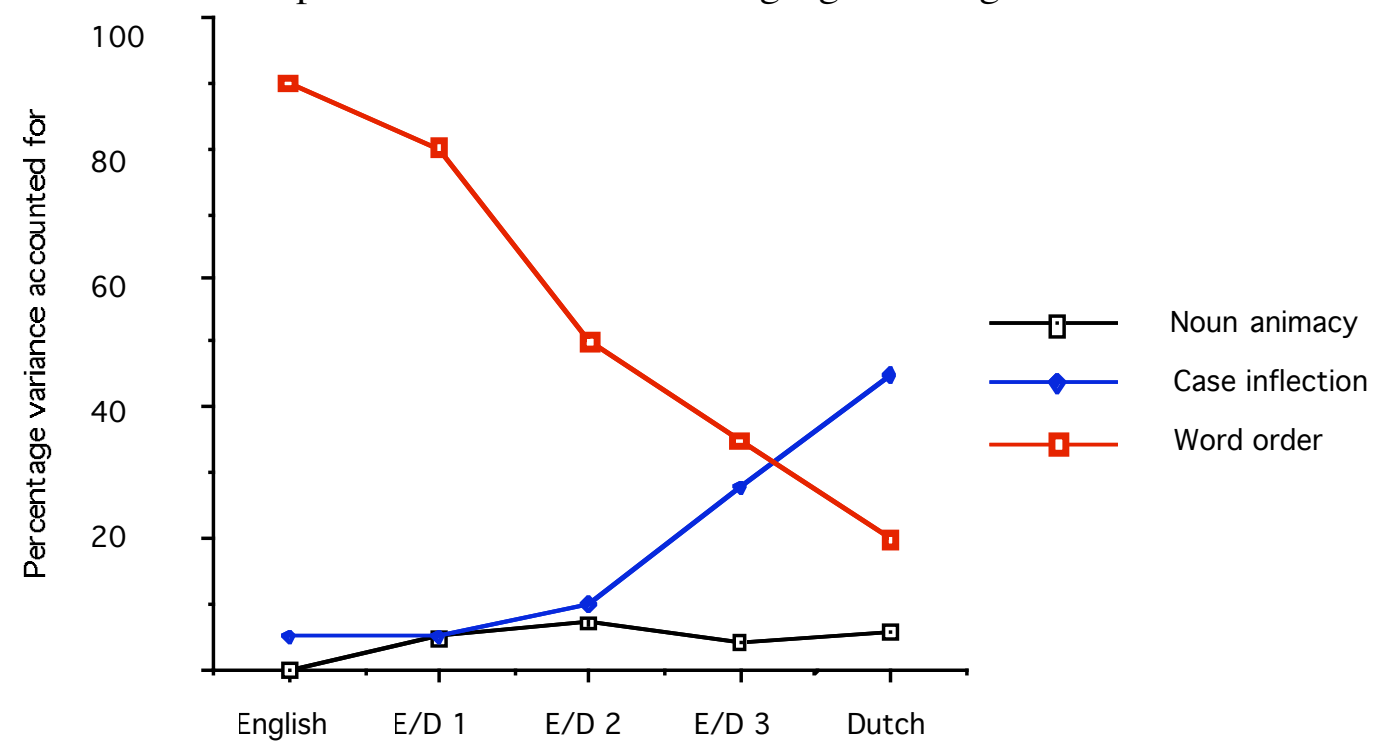

Figure 6: Changes in cue strength as English speakers learn Dutch (McDonald, 1987b). 


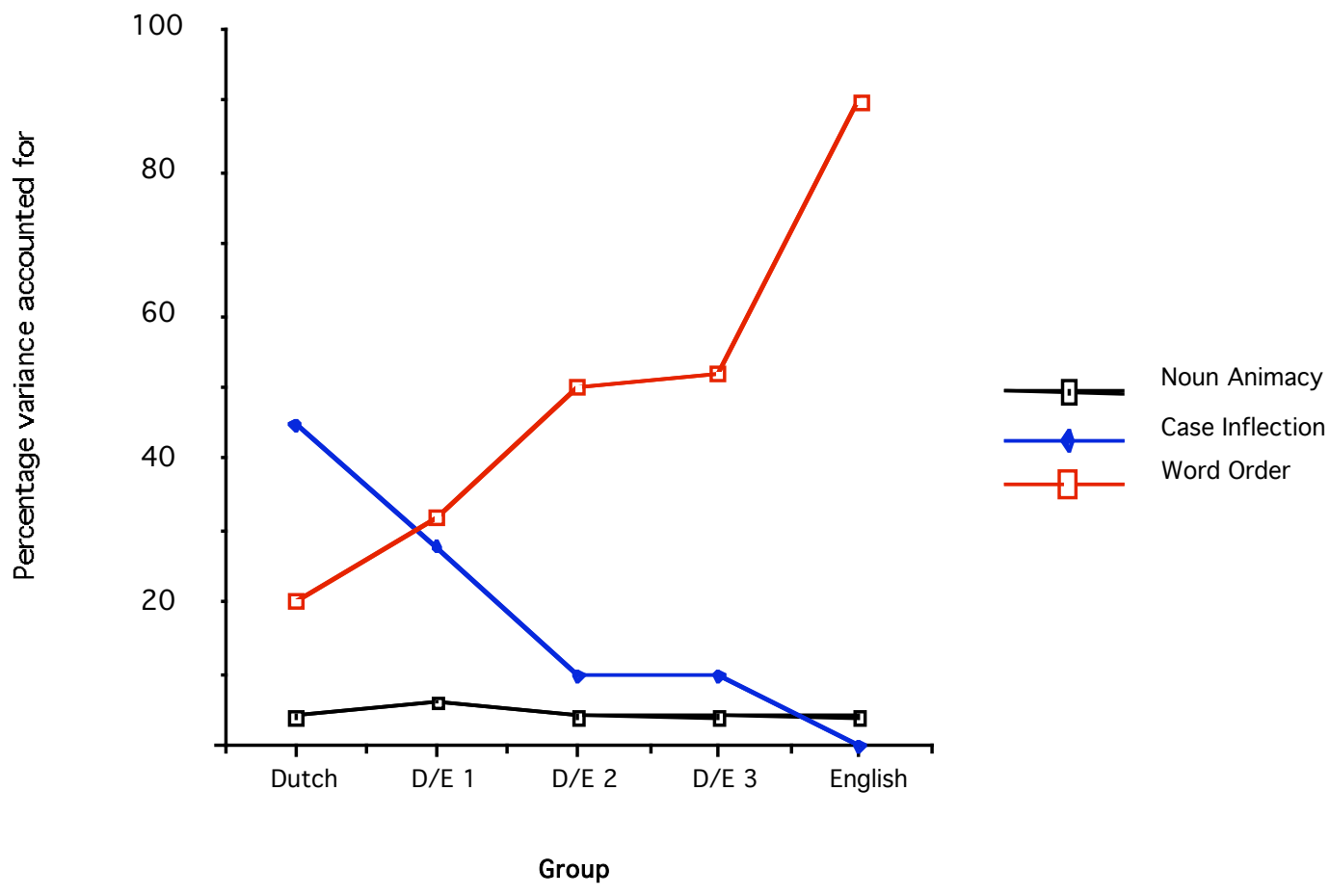

Figure 7: Changes in cue strength as Dutch speakers learn English (McDonald, 1987b).

Figure 1 depicted a set of connections between forms and functions for the processing of cues to sentence interpretation. It is possible to convert this intuitive analysis of the subject-marking system into an actual running network model. Janice Johnson and I have done this by giving the various surface cues specified in Figure 1 as input to a "recurrent" network of the type developed by Elman (1990). This network is able to simulate the learning of Dutch and English. The model takes as input a corpus of over 1000 sentences in each language. This corpus contains grammatical sentences from a wide variety of sentence types, including relative clauses, simple transitives, imperatives, subordinates, pronominalizations, and grammatical word order variations. After training in either language as L1, the model is given ungrammatical Competition Model sentences as test materials. At this point, we find exactly the types of cue interpretation patterns we saw in graphs like Figures 3 and 4 . In order to model second language learning, we then continue with a period of training with sentences from both languages and we then see exactly the pattern of cue development reported in Figures 6 and 7 from McDonald (McDonald, 1987b; McDonald, 1989).

\section{Neuronal Commitment}

Facts about brain development lead to a second major consequence for second language acquisition theory. As development progresses from childhood through adolescence, the various areas of the brain lose their plasticity and their capacity for radically new forms of learning (Booth et al., 1999). When children are young, they can easily recover from the loss of large areas of cerebral cortex. However, similar losses in adulthood can lead to aphasia. This declining plasticity of the brain is at the root of the difficulties that older adults have in acquiring full competence in L2. This slow decline in flexibility is often discussed in terms of the theory of critical periods (Lenneberg, 1967). The idea that adults cannot learn second languages is easily over-stated. Nonetheless, it is important to 
recognize that the plasticity of the brain places important limits on what the adult has to do to achieve successful second language acquisition. Johnson and Newport $(1989 ; 1991)$, and DeKeyser (this volume) have emphasized the extent to which adult second language learners may fail to achieve successful control over L2. For these learners, continued exposure to English does not appear to lead to continued learning. In practice, the language attainment of these learners becomes fossilized or frozen at a fairly low level.

These findings can be understood in terms of the theory of neuronal commitment. We know that, even during infancy, areas involved in auditory processing and motor control are under intense pressure toward neural "commitment" (Werker, Gilbert, Humphrey, \& Tees, 1981). Once a local neural area has been committed, it then takes in large amounts of input data that tightly tune the activation weights. If a second language is then to be imposed upon this preexisting neural structure, it would directly interfere with the established set of weights. In fact, the parasitic nature of second language learning blocks any such "catastrophic" interference of L2 onto L1. However, a full control over L2 requires the learner to reduce this parasitism and to automatize L2 processes apart from L1 processes.

\section{Automaticity}

Like other cognitive accounts, the Competition Model recognizes the importance of basic principles of learning such as the power law, and the fact that the best predictor of level of learning is time on task. These principles underscore the fact that learning a second language involves developing a automatic level of access to words and syntactic patterns that can guarantee fluency and accuracy (Skehan and Foster, this volume). There are several Competition Model demonstrations of this fact. Kilborn (1989) has shown that even fully competent bilinguals tend to process sentences in their L2 more slowly than monolinguals. However, when monolinguals are asked to listen to sentences under conditions of white noise, their reaction times are identical to those of bilinguals not subjected to noise. Similarly Blackwell and Bates (1995) and Miyake, Carpenter, and Just (1994) have shown that, when subjected to conditions of noise, normals process sentences much like aphasics not subjected to noise. Gerver (1974) and Seleskovitch (1976) have reported parallel results for the effects of noise on simultaneous interpretation.

The Competition Model provides an account of sentence processing difficulty that stems directly from the notion of competition. Consider a German sentence that begins with an initial noun that is ambiguously marked for case, such as Die Mutter küsst der Vater "The father kissed the mother." Because a noun like "die Mutter" could be in either the nominative or accusative case, the listener does not know initially whether to establish the perspective as agent or patient. Because there is a strong tendency for initial nouns to be agents in German, this reading is favored. However, a cautious listener will continue to maintain the alternative assignment in memory until the clause is complete. There are many examples of competing interpretations of this type. The parsing model promoted by Frazier and colleagues (Frazier, 1987; Frazier \& Rayner, 1990) treats ambiguity resolution in terms of garden-pathing, rather than competition. However, other researchers (Altmann, Garnham, \& Dennis, 1992; Juliano \& Tanenhaus, 1993; Small, Cottrell, \& Tanenhaus, 1988; Taraban \& McClelland, 1988; Trueswell \& Tanenhaus, 1992; Trueswell, Tanenhaus, \& Kello, 1993) have found that linguistic processing is best viewed in terms of an ongoing competition between alternatives.

\section{Functional Circuits}


In order to solve the problems caused by commitment and parasitism, the adult second language learner must rely on another dimension of neuronal processing. This is the use of the functional neural circuits that support rehearsal, monitoring, imagery, and reinforcement. These circuits allow the adult learner to maintain focused contact with crucial pieces of the input that can be used to correct problems with negative transfer and to reduce the parasitism of L2 on L1. By listening to high-quality input, working on meaningful relations in dialogs, and shadowing native speaker productions, the learner is able to make repeated us of the phonological loop and mental imagery. We know that neural networks can be effecitvely trained through repeated presentation of stimuli. This suggests that repeated use of these functional circuits should help recruit the residual neuronal resources that are still available to adult learners.

The prototypical case of a functional neural circuit is the phonological or rehearsal loop (Gathercole \& Baddeley, 1993; Geschwind, 1970). This loop involves an activation of auditory cortex in the temporal lobe, processing of this input through parietal and temporal cortex, activation of the corresponding articulatory form of the word in motor cortex or premotor cortex, and storage of this material in dorsolateral prefrontal cortex (Cohen et al., 1997). We can think of individual differences in working memory as variations in the extent to which people make use of this particular circuit. King and Just (1991) present evidence that individual differences in working memory are correlated with sentence processing in Competition Model type sentences, as well as variations in relative clause structure (MacWhinney \& Pléh, 1988).

Researchers in neuropsychology have only just now begun to explore the ways in which positive affect can help support mental processing in the phonological loop or in similar processing loops. When we consider the long hours that a teen-age boy will spend absorbed in video games, we begin to think about the ways in which this activity may release rewarding substances such as dopamine in the brain. The release of these chemicals provides further support for the activity.

There is evidence that people find language use itself reinforcing. Many of us love to talk, even when there is nothing important to talk about. Language use is reinforcing, physically, socially, and cognitively. Bedtime monologues, word games, songs, and poems provide further evidence for the reinforcing nature of language. How this reinforcement actually works in terms of structures like the amygdala and the basal ganglia is something we are only now beginning to understand.

To the degree that adult second language learners can use reinforcing loops to participate in this self-rewarding use of language, they may succeed in overcoming declining neuronal plasticity and the parasitism of L2 on L1. Whether classroom use of language serves to promote these reinforcing loops is a matter that needs to be studied more closely.

\section{Perspective-taking}

A final aspect of neural processing that we need to consider is the way in which language imposes demands on during sentence interpretation. For language learners, these demands will interact with other aspects of their cognitive system, including working memory, vocabulary size, and automaticity.

Our raw memory for strings of nonsense words is not more than about four. However, when words come in meaningful groups, we can remember dozens of words, even when the message is unfamiliar. The most likely candidate for this additional storage is some form of conceptual representation (Lombardi \& Potter, 1992). This process begins 
with the identification of a starting point (MacWhinney, 1977) or perspective from which the entire clause can be interpreted. In English, this is usually the subject. As new elements come in, they are linked up to this starting point. For example, if the initial phrase of the utterance is "the black dog", then the noun "dog" is taken as the perspective and the adjective "black" is linked to dog through the modifier valence relation. The formation of the link between "black" and "dog" involves more that the simple positional relation of two words. Instead the adjective is applied to the noun on the conceptual level and an image of a black dog is activated. As long as verbal material can successfully access an integrated conceptual representation, it exacts no additional storage cost. However, sometimes verbal elements will "stack up" in a way that exceeds a learner's capacity. Even a single centerembedding like "the dog that the flea bit chased the cat" involves more storage and restructuring than a subject relative like "the dog that bit the flea chased the cat." Studies of Hungarian (MacWhinney \& Pléh, 1988) and Japanese (Hakuta, 1982) show that the stacking up of unlinked noun phrases can be even worse in SOV languages. Second language learners who have problems coping with such conceptually opaque structures may well have problems with these particular languages (MacWhinney, 1996).

\section{The Context}

The third component of the language learning system, is the interactional context. To some degree, this context is given by the facts of social life. If a young child is reared in isolation, language acquisition will be difficult (Curtiss, 1977). If the child is given strong scaffolding and support, acquisition will be facilitated (Snow, 1995). For the second language learner, the situation is very different. In the classroom, a learner has little control over the interactional context. In this framework, successful learning strategies amount to little more than paying attention to the teacher, taking good notes, and keeping up with assignments. The goal in all of this is to maximize input and to occasionally get a chance to produce utterances. If there is a language learning laboratory, the student can use videotapes, audiotapes, and computerized lessons as further sources of input.

Even in more naturalistic contexts, the adult often does not have access to the rich system of social support that provides high quality language input to the child (Locke, 1995; Snow, 1995). In some situations, the learner is overtly excluded from close personal interactions. In such cases, it becomes difficult to engage in the type of rich ongoing use of language that can maximally support learning. To compensate for this, the learner can develop a system of "autosupport" that uses functional neural circuits and carefully recruited social contexts as ways of maximizing the outcome of language learning. Concrete strategies include listening to television, radio, and movies, rehearsing taped dialogs, practicing new lexical items, and direct study of grammatical theory. These activities allow the adult learner to remain in contact with the input in ways that promote the functioning of neuronal loops for rehearsal, memory, and learning.

In summary, the Competition Model framework we have examined provides several tools for understanding second language learning. First, the underlying functionalist model of language processing makes direct predictions about impact of the input on the course of acquisition of specific structures in comprehension and production. Second, the neuronal model of learner emphasizes the roles of transfer, automatization, and parasitism in learning of the L2. Third, findings regarding plasticity and commitment can help us understand why adults have difficulties blocking transfer and parasitism in certain cases. At the same time, learning practices can provide forms of auto-support that compensate for the adult learner's loss of neuronal plasticity and full social support. 


\section{$\underline{\text { References }}$}

Altmann, G., Garnham, A., \& Dennis, Y. (1992). Avoiding the garden path: Eye movements in context. Journal of Memory and Language, 31, 685-712.

Anderson, N. (1982). Methods of information integration theory. New York: Academic Press.

Andonova, E. (1998). Sentence interpretation in Bulgarian: The contribution of animacy, Proceedings of the 20th Annual Meeting of the Cognitive Science Society (pp. 54-58). Mahwah, NJ: Lawrence Erlbaum Associates.

Bates, E., Chen, S., Tzeng, O., Li, P., \& Opie, M. (1991). The noun-verb problem in Chinese aphasia. Brain and Language, 41, 203-233.

Bates, E., \& MacWhinney, B. (1981). Second language acquisition from a functionalist perspective: Pragmatic, semantic and perceptual strategies. In H. Winitz (Ed.), Annals of the New York Academy of Sciences conference on native and foreign language acquisition (pp. 190-214). New York: New York Academy of Sciences.

Bates, E., MacWhinney, B., Caselli, C., Devescovi, A., Natale, F., \& Venza, V. (1984). A crosslinguistic study of the development of sentence interpretation strategies. Child Development, 55, 341-354.

Bates, E., McNew, S., MacWhinney, B., Devescovi, A., \& Smith, S. (1982). Functional constraints on sentence processing: A cross-linguistic study. Cognition, 11, 245-299.

Bavin, E., \& Shopen, T. (1989). Warlpiri children's processing of transitive sentences. In B. MacWhinney \& E. Bates (Eds.), The crosslinguistic study of sentence processing (pp. 185-208). New York: Cambridge University Press.

Berlin, B., \& Kay, P. (1969). Basic Color Terms: Their Universality and Evolution. Berkeley: University of California Press.

Blackwell, A., \& Bates, E. (1995). Inducing agrammatic profiles in normals: Evidence for the selective vulnerability of morphology under cognitive resource limitation. Journal of Cognitive Neuroscience, 7, 228-257.

Bloom, L. (1974). Talking, understanding, and thinking. In R. Schiefelbusch \& L. Lloyd (Eds.), Language perspectives: Acquisition, retardation, and intervention . Baltimore: University Park Press.

Booth, J. R., MacWhinney, B., Thulborn, K. R., Sacco, K., Voyvodic, J., \& Feldman, H. (1999). Functional organization of activation patterns in children: Whole brain fMRI imaging during three different cognitive tasks. Progress in Neuropsychopharmocology and Biological Psychiatry, 23, 669-682.

Chomsky, N. (1965). Aspects of the theory of syntax. Cambridge, MA: MIT Press.

Cohen, D. D., Perlstein, W. M., Braver, T. S., Nystrom, L. E., Noll, D. C., Jonides, J., \& Smith, E. (1997). Temporal dynamics of brain activation during a working memory task. Nature, 386, 604-608.

Curtiss, S. (1977). Genie: A psycholinguistic study of a modern-day wild child. New York: Academic Press.

de Bot, K., \& van Montfort, R. (1988). 'Cue-validity' in het Nederlands als eerste en tweede taal. Interdisciplinair Tijdschrift voor Taal en Tekstwetenschap, 8, 111-120.

De Houwer, A. (1995). Bilingual language acquisition. In P. Fletcher \& B. MacWhinney (Eds.), The Handbook of Child Language (pp. 219-250). Oxford: Blackwell.

Elman, J. (1990). Finding structure in time. Cognitive Science, 14, 179-212.

Fausett, L. (1994). Fundamentals of neural networks. Englewood Cliffs, NJ: Prentice Hall.

Flege, J., \& Davidian, R. (1984). Transfer and developmental processes in adult foreign language speech production. Applied Psycholinguistics, 5, 323-347. 
Flege, J., Takagi, J., \& Mann, V. (1995). Japanese adults can learn to produce English "r" and "1" accurately. Language Learning, 39, 23-32.

Fodor, J. (1983). The modularity of mind: An essay on faculty psychology. Cambridge, Mass.: M. I. T. Press.

Frazier, L. (1987). Sentence processing: A tutorial review. In M. Coltheart (Ed.), Attention and performance XII (pp. 601-681). London, UK: Lawrence Erlbaum Associates.

Frazier, L., \& Rayner, K. (1990). Taking on semantic commitments: Processing multiple meanings vs. multiple senses. Journal of Memory and Language, 29, 181-200.

Gass, S. (1987). The resolution of conflicts among competing systems: A bidirectional perspective. Applied Psycholinguistics, 8, 329-350.

Gathercole, V., \& Baddeley, A. (1993). Working memory and language. Hillsdale, NJ: Lawrence Erlbaum Associates.

Gazzaniga, M. (Ed.). (1997). The cognitive neurosciences. Cambridge, MA: MIT Press.

Gerver, D. (1974). The effects of noise on the performance of simultaneous interpreters: Accuracy of performance. Acta Psychologica, 38, 159-167.

Geschwind, N. (1970). The organization of language and the brain. Science, 170, 940944.

Grainger, J., \& Dijkstra, T. (1992). On the representation and use of language information in bilinguals. In R. Harris (Ed.), Cognitive processing in bilinguals . Amsterdam: North-Holland.

Grosjean, F. (1982). Life with two languages: An introduction to bilingualism. Cambridge, MA: Harvard University Press.

Hakuta, K. (1982). Interaction between particles and word order in the comprehension of simple sentences in Japanese children. Developmental Psychology, 18, 62-76.

Hancin-Bhatt, B. (1994). Segment transfer: a consequence of a dynamic system. Second Language Research, 10, 241-269.

Harrington, M. (1987). Processing transfer: language-specific strategies as a source of interlanguage variation. Applied Psycholinguistics, 8, 351-378.

Harrington, M. (1992). Working memory capacity as a constraint on L2 development. In R. Harris (Ed.), Cognitive processing in bilinguals . Amsterdam: North Holland.

Ijaz, H. (1986). Linguistic and cognitive determinants of lexical acquisition in a second language. Language Learning, 36, 401-451.

Johnson, J., \& Newport, E. (1989). Critical period effects in second language learning: The influence of maturational state on the acquisition of English as a second language. Cognitive Psychology, 21, 60-99.

Johnson, J. S., \& Newport, E. L. (1991). Critical period effects on universal properties of language: the status of subjacency in the acquisition of a second language. Cognition, $39,215-258$.

Juliano, C., \& Tanenhaus, M. (1993). Contingent frequency effects in syntactic ambiguity resolution, Proceedings of the Fifteenth Annual Conference of the Cognitive Science Society (pp. 593-598). Hillsdale, NJ: Lawrence Erlbaum.

Kail, M. (1989). Cue validity, cue cost, and processing types in French sentence comprehension. In B. MacWhinney \& E. Bates (Eds.), The crosslinguistic study of language processing (pp. 77-117). New York: Cambridge University Press.

Kempe, V., \& MacWhinney, B. (1998). The acquisition of case-marking by adult learners of Russian and German. Studies in Second Language Acquisition, 20, 543-587.

Kilborn, K. (1989). Sentence processing in a second language: The timing of transfer. Language and Speech, 32, 1-23.

Kilborn, K., \& Cooreman, A. (1987). Sentence interpretation strategies in adult DutchEnglish bilinguals. Applied Psycholinguistics, 8, 415-431.

Kilborn, K., \& Ito, T. (1989). Sentence processing in Japanese-English and DutchEnglish bilinguals. In B. MacWhinney \& E. Bates (Eds.), The crosslinguistic study of sentence processing (pp. 257-291). New York: Cambridge University Press. 
King, J., \& Just, M. (1991). Individual differences in syntactic processing: the role of working memory. Journal of Memory and Language, 30, 580-602.

Kroll, J., \& Sholl, A. (1992). Lexical and conceptual memory in fluent and nonfluent bilinguals. In R. Harris (Ed.), Cognitive processing in bilinguals (pp. 191-206). Amsterdam: North-Holland.

Lenneberg, E. H. (1967). Biological foundations of language. New York: Wiley.

Levelt, W. J. M. (1989). Speaking: From intention to articulation. Cambridge, MA: MIT Press.

Li, P., Bates, E., Liu, H., \& MacWhinney, B. (1992). Cues as functional constraints on sentence processing in Chinese. In H. Chen \& O. Tzeng (Eds.), Language processing in Chinese (pp. 207-236). Amsterdam: North-Holland.

Liu, H., Bates, E., \& Li, P. (1992). Sentence interpretation in bilingual speakers of English and Chinese. Applied Psycholinguistics, 13, 451-484.

Locke, J. L. (1995). Development of the capacity for spoken language. In P. Fletcher \& B. MacWhinney (Eds.), The handbook of child language . Oxford: Basil Blackwell.

Lombardi, L., \& Potter, M. (1992). The regeneration of syntax in short term memory. Journal of Memory and Language, 31, 713-733.

MacDonald, M., \& MacWhinney, B. (1990). Measuring inhibition and facilitation from pronouns. Journal of Memory and Language, 29, 469-492.

MacWhinney, B. (1974). How Hungarian children learn to speak. , University of California, Berkeley.

MacWhinney, B. (1977). Starting points. Language, 53, 152-168.

MacWhinney, B. (1987). The Competition Model. In B. MacWhinney (Ed.), Mechanisms of language acquisition (pp. 249-308). Hillsdale, NJ: Lawrence Erlbaum.

MacWhinney, B. (1989). Competition and lexical categorization. In R. Corrigan, F. Eckman, \& M. Noonan (Eds.), Linguistic categorization (pp. 195-242). New York: Benjamins.

MacWhinney, B. (1996). Language specific prediction in foreign language acquisition. Language Testing, 12, 292-320.

MacWhinney, B. (1998). Models of the emergence of language. Annual Review of Psychology, 49, 199-227.

MacWhinney, B., \& Bates, E. (1978). Sentential devices for conveying givenness and newness: A cross-cultural developmental study. Journal of Verbal Learning and Verbal Behavior, 17, 539-558.

MacWhinney, B., \& Bates, E. (Eds.). (1989). The crosslinguistic study of sentence processing. New York: Cambridge University Press.

MacWhinney, B., Bates, E., \& Kliegl, R. (1984). Cue validity and sentence interpretation in English, German, and Italian. Journal of Verbal Learning and Verbal Behavior, 23, 127-150.

MacWhinney, B., \& Osman-Sági, J. (1991). Inflectional marking in Hungarian aphasics. Brain and Language, 41, 165-183.

MacWhinney, B., Osman-Sági, J., \& Slobin, D. (1991). Sentence comprehension in aphasia in two clear case-marking languages. Brain and Language, 41, 234-249.

MacWhinney, B., \& Pléh, C. (1988). The processing of restrictive relative clauses in Hungarian. Cognition, 29, 95-141.

MacWhinney, B., \& Pléh, C. (1997). Double agreement: Role identification in Hungarian. Language and Cognitive Processes, 12, 67-102.

MacWhinney, B., Pléh, C., \& Bates, E. (1985). The development of sentence interpretation in Hungarian. Cognitive Psychology, 17, 178-209.

MacWhinney, B. J., Leinbach, J., Taraban, R., \& McDonald, J. L. (1989). Language learning: Cues or rules? Journal of Memory and Language, 28, 255-277. 
Maratsos, M., \& Chalkley, M. (1980). The internal language of children's syntax: The ontogenesis and representation of syntactic categories. In K. Nelson (Ed.), Children's language: Volume 2 (pp. 127-214). New York: Gardner.

Massaro, D. (1987). Speech perception by ear and eye. Hillsdale, NJ: Lawrence Erlbaum.

McDonald, J. L. (1986). The development of sentence comprehension strategies in English and Dutch. Journal of Experimental Child Psychology, 41, 317-335.

McDonald, J. L. (1987a). Assigning linguistic roles: The influence of conflicting cues. Journal of Memory and Language, 26, 100-117.

McDonald, J. L. (1987b). Sentence interpretation in bilingual speakers of English and Dutch. Applied Psycholinguistics, 8, 379-414.

McDonald, J. L. (1989). The acquisition of cue-category mappings. In B. MacWhinney \& E. Bates (Eds.), The crosslinguistic study of language processing (pp. 375-396). New York: Cambridge University Press.

McDonald, J. L., \& Heilenman, K. (1991). Determinants of cue strength in adult first and second language speakers of French. Applied Psycholinguistics, 12, 313-348.

McDonald, J. L., \& MacWhinney, B. (1989). Maximum likelihood models for sentence processing research. In B. MacWhinney \& E. Bates (Eds.), The crosslinguistic study of sentence processing (pp. 397-421). New York: Cambridge University Press.

McDonald, J. L., \& MacWhinney, B. J. (1995). The time course of anaphor resolution: Effects of implicit verb causality and gender. Journal of Memory and Language, 34, 543-566.

McLaughlin, B. (1982). Second-language learning and bilingualism in children and adults. In S. Rosenberg (Ed.), Handbook of applied psycholinguistics: Major thrusts of research and theory. Hillsdale, NJ: Lawrence Erlbaum Associates.

Miyake, A., Carpenter, P., \& Just, M. (1994). A capacity approach to syntactic comprehension disorders: Making normal adults perform like aphasic patients. Cognitive Neuropsychology, 11, 671-717.

O'Malley, M., \& Chamot, A. (1990). Learning strategies in second language acquisition. Cambrdige: Cambridge University Press.

Oden, G., \& Massaro, D. (1978). Integration of featural information in speech perception. Psychological Review, 85, 172-191.

Sasaki, Y. (1994). Paths of processing strategy transfers in learning Japanese and English as foreign languages. Studies in Second Language Acquisition, 16, 43-72.

Sasaki, Y. (1997a). Individual variation in a Japanese sentence comprehension task: Form, functions, and strategies. Applied Linguistics, 18, 508-537.

Sasaki, Y. (1997b). Material and presentation condition effects on sentence interpretation task performance: Methodological examinations of the competition experiment. Second Language Research, 13, 66-91.

Seleskovitch, D. (1976). Interpretation: A psychological approach to translating. In R. W. Brislin (Ed.), Translation: Application and Research. New York: Gardner.

Seliger, H. (1989). Semantic transfer constraints on the production of English passives by Hebrew-English bilinguals. In H. Dechert \& M. Raupach (Eds.), Transfer in language production. Norwood: NJ: Ablex.

Service, E., \& Craik, F. I. M. (1993). Differences between young and older adults in learning a foreign vocabulary. Journal of Memory and Language, 32, 608-623.

Small, S., Cottrell, G., \& Tanenhaus, M. (Eds.). (1988). Lexical ambiguity resolution. San Mateo, CA: Morgan Kaufmann.

Snow, C. (1995). Issues in the study of input: Finetuning, universality, individual and developmental differences, and necessary causes. In P. Fletcher \& B. MacWhinney (Eds.), The handbook of child language (pp. 180-193). Oxford: Blackwells.

Sokolov, J. L. (1988). Cue validity in Hebrew sentence comprehension. Journal of Child Language, 15, 129-156. 
Sokolov, J. L. (1989). The development of role assignment in Hebrew. In B. MacWhinney \& E. Bates (Eds.), The crosslinguistic study of sentence processing (pp. 158-184). New York: Cambridge.

Stockwell, R., Bowen, J., \& Martin, J. (1965). The grammatical structures of English and Spanish. Chicago: University of Chicago Press.

Taman, H. (1993). The utilization of syntactic, semantic, and pragmatic cues in the assignment of subject role in Arabic. Applied Psycholinguistics, 14, 299-317.

Taraban, R., \& McClelland, J. L. (1988). Constituent attachment and thematic role assignment in sentence processing: Influences of content-based expectations. Journal of Memory and Language, 27, 597-632.

Trévise, A. (1986). Is it transferable, topicalization? In K. Kellerman \& M. Sharwood Smith (Eds.), Crosslinguistic influence in second language acquisition (pp. 186-206). New York: Pergamon.

Trueswell, J., \& Tanenhaus, M. (1992). Consulting temporal context during sentence comprehension: Evidence from the monitoring of eye movements in reading, Proceedings of the Fourteenth Annual Conference of the Cognitive Science Society . Hillsdale, NJ: Lawrence Erlbaum Associates.

Trueswell, J. C., Tanenhaus, M. K., \& Kello, C. (1993). Verb-specific constraints in sentence processing: Separating effects of lexical preference from garden-paths. Journal of Experimental Psychology: Learning, Memory, and Cognition, 19(3), 528553.

Tzeng, O., Chen, S., \& Hung, D. (1991). The classifier problem in Chinese aphasia. Brain and Language, 41, 184-202.

Vaid, J., \& Pandit, R. (1991). Sentence interpretation in normal and aphasic Hindi speakers. Brain and Language, 41, 250-274.

Werker, J. F., Gilbert, J. H. V., Humphrey, K., \& Tees, R. C. (1981). Developmental aspects of cross-language speech perception. Child Development, 52, 349-355. 